\title{
Psychological distress, physical illness and risk of myocardial infarction in the Caerphilly study
}

\author{
F. RASUL ${ }^{1}$, S. A. STANSFELD ${ }^{1 *}$, G. DAVEY SMITH ${ }^{2}$, Y. BEN SHLOMO ${ }^{2}$ \\ AND J. GALLACHER ${ }^{3}$ \\ ${ }^{1}$ Centre for Psychiatry, Wolfson Institute of Preventive Medicine, Barts and the London, Queen Mary's \\ School of Medicine and Dentistry, University of London; ${ }^{2}$ Department of Social Medicine, University of \\ Bristol; ${ }^{3}$ Department of Epidemiology and Public Health, University of Wales College of Medicine, \\ Cardiff, $U K$
}

\begin{abstract}
Background. Studies have found associations between psychological distress (PD) and increased risk of myocardial infarction (MI). However, it is not clear whether the relationship reflects the subtle influence of pre-existing illness on both PD and MI. This study examines the association between PD and MI in a prospective epidemiological study of 1864 middle-aged men to examine if the association is explained by existing illness.
\end{abstract}

Method. This study was a prospective cohort study modelling the association between PD, measured using the 30-item General Health Questionnaire (GHQ) and non-fatal myocardial infarction (NFMI) and fatal/non-fatal myocardial infarction (FNFMI).The relationship was modelled in a series of logistic regression models adjusted for age, then cigarette smoking, then social position, and finally for all sociodemographic characteristics, coronary heart disease (CHD) risk factors, and baseline CHD.

Results. PD was associated with a $70 \%$ and $68 \%$ increased risk of NFMI and FNFMI in fully adjusted analysis. However, PD was not associated with an increased risk of NFMI and FNFMI in analyses excluding those with baseline CHD. Further, being psychologically distressed and physically ill was associated with a greater than twofold risk of NFMI and FNFMI, $2 \cdot 37$ (95\% CI $1 \cdot 33-4 \cdot 20)$ and $2 \cdot 33(95 \%$ CI $1 \cdot 32-4 \cdot 12)$ respectively.

Conclusion. This study suggests that PD is a moderator of the increased risk of MI associated with existing physical illness. PD in men who are physically ill is a marker of an underlying chronic physical illness. The prospective association of PD with MI is not independent of baseline physical illness.

\section{BACKGROUND}

Mild to moderate depression, measured as general psychological distress (PD), has been shown to be associated with increased risk of coronary heart disease (CHD) events. There is a growing body of evidence from studies of healthy community-dwelling populations that

\footnotetext{
* Address for correspondence: Professor Stephen A. Stansfeld, Centre for Psychiatry, Barts \& The London School of Medicine and Dentistry, Old Anatomy Building, Charterhouse Square, London EC1M 6BQ, UK.

(Email: S.A.Stansfeld@qmul.ac.uk)
}

suggests that PD predicts incident CHD independently of sociodemographic characteristics, CHD risk factors, health behaviours and physical illness. Systematic reviews have shown that PD, specifically depressive disorder, is a consistent predictor of CHD (Hemingway \& Marmot, 1999; Wulsin \& Singal, 2003). Prospective epidemiological studies using the General Health Questionnaire (GHQ) have shown that PD was associated with an increased risk of CHD (Stansfeld et al. 2002) even after adjustment for baseline physical illness (Rasul et al. 2004). Other 
studies using different measures of PD have found up to threefold-increased risk of CHD in men even after adjustment for CHD risk factors and other confounders (Hippisley-Cox et al. 1998). However, not all studies have found a positive association between PD and incident CHD (Wulsin et al. 2005) and a recent metaanalysis reserves judgement on the association because of inconsistent adjustment for severity of CHD and risk factors across studies (Nicholson et al. 2006).

CHD in these studies was defined as a composite of International Classification of Disease, Ninth Revision (ICD-9) codes 410-414, namely acute MI, other acute and sub-acute forms of CHD, old MI, angina pectoris, and other forms of chronic CHD. The disadvantage of this classification is its heterogeneity, including outcomes such as angina pectoris that are susceptible to response bias.

However, some studies have examined the association between PD and CHD using more specific outcomes such as fatal and non-fatal MI. For example, in a study of 730 men and women in Glostrup, Denmark (Barefoot \& Schroll, 1996) a 2-s.D. increase in the obvious depression scale a depression subscale of the Minnesota Multiphasic Personality Inventory (MMPI) was associated with a $71 \%$ increased risk of non-fatal MI. This finding was unaffected by adjustment for CHD risk factors and baseline physical illness. The Precursors Study (Ford et al. 1998), of 1190 male medical students followed up for 40 years, showed that self-report of clinical depression was associated with over twice the increased risk of 10-year MI even after taking into account baseline CHD factors, health behaviours, previous MI and diabetes.

The Kuopio Ischaemic Heart Disease Study (Everson et al. 1996), using hopelessness as a measure of distress, found that high hopelessness scores were associated with an increased risk for a first MI, relative to men scoring low on the hopelessness measure. The increased risk remained after adjusting for biological, behavioural, and sociodemographic factors, perceived health status, depression, social support, cancer, history of cardiovascular disease (CVD), and respiratory disease. Men with moderate scores, compared with men with low scores on the hopelessness measure, showed a $20-30 \%$ increased risk of MI. In another study, Pratt and co-workers (1996), using the diagnostic interview schedule to assess major depressive episode (MDE), showed that the odds of MI in respondents with a history of dysphoria were $2 \cdot 1$ times more likely and in respondents with MDE 4.5 times more likely than in respondents with no history of dysphoria. This increased risk was independent of major coronary risk factors, comorbid psychiatric disorders and psychotropic drug use. However, a limitation of this study was that the outcome measure, MI, was based upon self-report and therefore subject to misclassification.

The relationship between PD and MI in men has been less apparent in some other studies. In the Normative Aging Study a high depressive symptom score on the depression subscale of the MMPI-2 was associated with two and half times the risk of non-fatal MI. Further, in the Systolic Hypertension in the Elderly program study a 5unit increase in the Centre for Epidemiologic Studies-Depression (CES-D) scale was associated with a $20 \%$ increased risk of fatal and non-fatal MI in women but not in men (Wassertheil-Smoller et al. 1996). Thus, although there is considerable evidence of an association between PD and CHD, the findings are not consistent across studies.

Further, follow-up of patients post MI has demonstrated that PD is not only a potential risk factor for onset of CHD but is also associated with a worse prognosis compared with patients without PD (Carney et al. 1995; Glassman \& Shapiro, 1998; Parashar et al. 2006). In the light of these prognostic findings the role of prior physical illness needs to be determined in the association between PD and CHD, as some studies suggest that the association between PD and CHD is explained after adjustment for baseline physical illness (Mendes de Leon et al. 1998). Thus one potential explanation that is relatively unexplored for the association of PD and $\mathrm{MI}$ is confounding by pre-existing physical illness that predicts both PD and, independently, MI.

The aim of this study is to examine the association between PD and non-fatal MI (NFMI) and fatal/non-fatal MI (FNFMI), hypothesizing increased MI risk in psychologically distressed compared with non-distressed respondents, and to examine the influence of clinically identified physical ill health in this association. An 
innovation of this study is that CHD at baseline and MI outcomes were based on non-subjective clinical measures.

\section{METHODS}

The Caerphilly Collaborative Heart Disease study is a prospective cohort study of cardiovascular disease in middle-aged men (45-59), recruited from the electoral register from the town of Caerphilly, Wales, UK, during 1979-1983. In phase I of the study 2818 men in this age group were identified from the electoral roll and invited to participate, a recruitment rate of $(89 \%)$. In phase II of the study during 1984-1988, 2398 men aged 49-64 participated in the study, including men in the original cohort recruited at phase I and men who had moved into the town in the interim period. The response rate for Phase II was $82 \%$. Further, details of the study are given elsewhere (Caerphilly and Speedwell Collaborative Group, 1984). For the purposes of this study phase II is used as the baseline.

\section{Measurement of exposure}

At phase II the following measurements were taken: medical history, smoking history, London School of Hygiene and Tropical Medicine (LSHTM) chest pain questionnaire, GHQ, height, weight, blood pressure measured with a random-zero sphygmomanometer, and a 12lead electrocardiogram (ECG). Full details of these and other measures are given elsewhere (Caerphilly and Speedwell Collaborative Group, 1984). Baseline physical illness includes the presence of either angina pectoris (LSHTM questionnaire), ECG ischaemia, diabetes mellitus or chronic bronchitis (MRC questionnaire).

Psychological distress was measured by the 30-item GHQ (Goldberg, 1972). A psychiatrist (SAS) validated the GHQ using the Clinical Interview Schedule (CIS) in a subsample of 97 men (Stansfeld et al. 1992). The CIS interview was carried out in the respondent's own home. The psychiatrist was blind to the GHQ score. A GHQ caseness threshold of $4 / 5$ gave a sensitivity and specificity of $71 \%$ each. From receiveroperating characteristic analysis respondents scoring 0-4 were considered not to be cases and those scoring 5 or greater were considered possible cases of minor psychiatric disorder.

\section{Measurement of outcomes}

The two MI outcomes used were NFMI and FNFMI. These outcomes were ascertained from three sources: the monitoring of hospital records by hospital activity analysis, the LSHTM chest pain questionnaire (Rose, 1962) and ECG examination of the subject. Hospital and home cases of non-fatal MI's were defined on the basis of World Health Organisation criteria, e.g. enzyme changes, serial ECG changes and typical clinical picture (myocardial infarction community register; WHO, 1976).

\section{Statistical methods}

The analyses were carried out on men who had complete data on all the variables used in the analyses $(n=1864)$. The association between baseline variables and GHQ status in men was analysed using $\chi^{2}$ tests for categorical variables and age-adjusted analyses of variance for continuous variables. Age was categorized into three categories (48-55, 56-60, 61-67); marital status as married, single, widowed, divorced, separated; smoking as never smoked, ex-smoker, cigarette/pipe, 1-14, 15-24, 25+; social class was based upon Registrar General classification I, II, III Non-Manual, III Manual, IV and V; employment status as employed, unemployed, self-employed, retired due to ill health. Continuous variables such as body mass index (BMI), systolic and diastolic blood pressure, glucose, fibrinogen, viscosity, white blood cell count, and cholesterol were all categorized into quintiles. Men were considered to have CHD if they had ECG changes with angina, ECG-diagnosed MI, or a history of MI. Diabetes was self-reported and chronic obstructive airway disease or asthma was inferred from use of bronchodilator drug use in the previous week.

A physical illness (one or more of CHD, diabetes or respiratory disease, or being retired on the grounds of ill health) PD variable was created, consisting of four categories. These were (1) GHQ negative \& healthy, (2) GHQ positive but healthy, (3) GHQ negative but ill, (4) GHQ positive and ill.

The association between PD and NFMI and FNFMI outcomes was analysed in a series of logistic regression models. Firstly, in an ageadjusted model, then in a model adjusted for age and smoking, then in a model adjusted 
Table 1. Baseline characteristics of General Health Questionnaire $(G H Q)$ positive and negative men

\begin{tabular}{|c|c|c|c|}
\hline$n=1864$ & $\begin{array}{c}\text { GHQ score } \geqslant 5 \\
405(21 \cdot 7 \%)\end{array}$ & $\begin{array}{c}\text { GHQ score }<5 \\
1459(78 \cdot 3 \%)\end{array}$ & $p$ \\
\hline Age & $57 \cdot 2(4 \cdot 5)$ & $57 \cdot 5(4 \cdot 5)$ & $0 \cdot 23$ \\
\hline $\begin{array}{l}\text { Marital status } \\
\text { Married } \\
\text { Single } \\
\text { Widowed } \\
\text { Divorced } \\
\text { Separated }\end{array}$ & $\begin{array}{c}352(86 \cdot 9 \%) \\
11(2 \cdot 7 \%) \\
21(5 \cdot 2 \%) \\
18(4 \cdot 4 \%) \\
3(0 \cdot 7 \%)\end{array}$ & $\begin{array}{c}1295(88 \cdot 5 \%) \\
71(4 \cdot 9 \%) \\
44(3 \cdot 0 \%) \\
45(3 \cdot 1 \%) \\
4(0 \cdot 3 \%)\end{array}$ & $0 \cdot 023$ \\
\hline $\begin{array}{l}\text { Social position } \\
\text { I } \\
\text { II } \\
\text { IIINM } \\
\text { IIIM } \\
\text { IV } \\
\text { V }\end{array}$ & $\begin{array}{c}19(4 \cdot 7 \%) \\
17(19 \cdot 5 \%) \\
33(8 \cdot 1 \%) \\
197(48 \cdot 6 \%) \\
58(14 \cdot 3 \%) \\
19(4 \cdot 7 \%)\end{array}$ & $\begin{array}{c}72(4 \cdot 9 \%) \\
264(18 \cdot 1 \%) \\
167(11 \cdot 4 \%) \\
685(46 \cdot 9 \%) \\
207(14 \cdot 2 \%) \\
64(4 \cdot 4 \%)\end{array}$ & $0 \cdot 57$ \\
\hline $\begin{array}{l}\text { Employment status } \\
\text { Employed } \\
\text { Unemployed } \\
\text { Self-employed } \\
\text { Retired (ill health) } \\
\text { Retired (other) }\end{array}$ & $\begin{array}{r}145(35 \cdot 8 \%) \\
83(20 \cdot 5 \%) \\
22(5 \cdot 4 \%) \\
112(27 \cdot 7 \%) \\
43(10 \cdot 6 \%)\end{array}$ & $\begin{array}{l}754(51 \cdot 7 \%) \\
198(13 \cdot 6 \%) \\
105(7 \cdot 2 \%) \\
175(12 \%) \\
227(15 \cdot 6 \%)\end{array}$ & $0 \cdot 01$ \\
\hline $\begin{array}{l}\text { Alcohol, cc/week } \\
\quad 0 \\
1-10 \\
11-46 \\
47-137 \\
138-228 \\
>229\end{array}$ & $\begin{array}{l}34(8 \cdot 4 \%) \\
67(16 \cdot 5 \%) \\
82(20 \cdot 2 \%) \\
91(22 \cdot 5 \%) \\
63(15 \cdot 6 \%) \\
68(16 \cdot 8 \%)\end{array}$ & $\begin{array}{c}84(5 \cdot 8 \%) \\
181(12 \cdot 4 \%) \\
295(20 \cdot 2 \%) \\
385(26 \cdot 4 \%) \\
234(16 \%) \\
280(19 \cdot 2 \%)\end{array}$ & $0 \cdot 06$ \\
\hline $\begin{array}{l}\text { Smoking } \\
\text { Never smoked } \\
\text { Ex-smoker } \\
\text { Cigarettes/pipe } \\
\text { 1-14 per day } \\
\text { 15-24 per day } \\
25+\text { per day }\end{array}$ & $\begin{array}{c}67(16 \cdot 5 \%) \\
146(36 \%) \\
42(10 \cdot 4 \%) \\
79(19 \cdot 5 \%) \\
48(11 \cdot 9 \%) \\
23(5 \cdot 7 \%)\end{array}$ & $\begin{array}{c}290(19 \cdot 9 \%) \\
146(38 \cdot 3 \%) \\
141(9 \cdot 7 \%) \\
211(14 \cdot 5 \%) \\
168(11 \cdot 5 \%) \\
89(6 \cdot 1 \%)\end{array}$ & $0 \cdot 17$ \\
\hline $\begin{array}{l}\text { Exercise, } \\
\mathrm{kcal} / \mathrm{month}\end{array}$ & $9781(11151)$ & $11356(10889)$ & $0 \cdot 01$ \\
\hline Chronic illness $^{\mathrm{a}}$ & $216(53 \cdot 3 \%)$ & $533(36 \cdot 5 \%)$ & $0 \cdot 01$ \\
\hline CHD & $148(36 \cdot 5 \%)$ & $390(26 \cdot 7 \%)$ & $\begin{array}{l}0.01 \\
0.35\end{array}$ \\
\hline $\begin{array}{l}\text { Diabetes } \\
\text { Respiratory } \\
\text { drugs }\end{array}$ & $\begin{array}{l}16(4 \%) \\
22(5 \cdot 4 \%)\end{array}$ & $\begin{array}{l}44(3 \%) \\
60(4 \cdot 1 \%)\end{array}$ & $\begin{array}{l}0 \cdot 35 \\
0 \cdot 25\end{array}$ \\
\hline $\begin{array}{l}\text { Body mass index, } \\
\mathrm{kg} / \mathrm{m}^{2}\end{array}$ & $26 \cdot 4(4)$ & $26 \cdot 5(3)$ & $0 \cdot 38$ \\
\hline $\begin{array}{l}\text { Systolic blood } \\
\text { pressure, } \mathrm{mmHg}\end{array}$ & $151(25)$ & $153(24)$ & $0 \cdot 14$ \\
\hline $\begin{array}{l}\text { Diastolic blood } \\
\text { pressure, } \mathrm{mmHg}\end{array}$ & $89(12)$ & $90(12)$ & $0 \cdot 17$ \\
\hline $\begin{array}{l}\text { White blood } \\
\text { cell count, } \times 10^{9} / 1\end{array}$ & $6 \cdot 83(1.94)$ & $6.58(1.84)$ & $0 \cdot 02$ \\
\hline Viscosity, $\mathrm{cP}$ & $1 \cdot 69(0 \cdot 10)$ & $1.67(0.09)$ & $0 \cdot 05$ \\
\hline Fibrinogen, g/l & $4 \cdot 10(0 \cdot 92)$ & $3.96(0.88)$ & $0 \cdot 01$ \\
\hline $\begin{array}{l}\text { Cholesterol, } \\
\mathrm{mmol} / \mathrm{l}\end{array}$ & $10 \cdot 0(2 \cdot 5)$ & $10 \cdot 3(2 \cdot 5)$ & $0 \cdot 13$ \\
\hline $\begin{array}{l}\text { Glucose, } \\
\mathrm{mmol} / 1\end{array}$ & $53(12)$ & $54(13)$ & $0 \cdot 26$ \\
\hline
\end{tabular}

Values are mean (s.D.).

CHD, Coronary heart disease.

a One or more of coronary heart disease, diabetes, respiratory disease, or retirement due to ill health. for age, smoking and social position and, finally, in a fully adjusted model adjusting for $\mathrm{BMI}$, forced expiratory volume $\left(\mathrm{FEV}_{1}\right)$, systolic and diastolic blood pressure, glucose, fibrinogen, viscosity, white blood cell count, cholesterol and baseline physical illness. Another logistic regression model included an interaction term between PD, and physical illness and both NFMI and FNFMI.

The interrelationship between PD, physical illness and NFMI, and FNFMI risk in men, was further assessed by examining the association of each category of the combined physical illness, PD variable with the MI outcomes in age and then sociodemographic and CHD risk-factoradjusted analysis.

\section{RESULTS}

The prevalence of PD in this cohort at Phase II was $22 \%$ (Stansfeld et al. 1992). There were 165 incident cases of NFMI and 171 cases of FNFMI in the follow-up period after phase II. The median follow-up time for NFMI and FNFMI was approximately 6 years and 2 months, and 6 years and 6 months, respectively.

Table 1 shows baseline (phase II) characteristics of psychologically distressed and nondistressed men. Compared with non-distressed men, psychologically distressed men were more likely to be widowed or divorced, have lower activity levels, and were unemployed or retired due to ill health (Table 1). Distressed men also had a higher prevalence of chronic illnesses and CHD. Further, distressed men had higher white blood cell counts, greater blood plasma viscosity, and higher fibrinogen levels compared with non-distressed men.

Table 2 shows baseline (phase II) characteristics of men who had a NFMI and a FNFMI in the follow-up period. Compared with men who did not have a NFMI, men who had a NFMI had a higher prevalence of chronic illnesses and CHD. Men who had a NFMI also had higher BMI, systolic and diastolic blood pressure, viscosity, fibrinogen and glucose level but lower cholesterol levels. These factors were similarly associated with men who had a FNFMI.

Psychological distress was associated with an increased risk of both NFMI and FNFMI (Table 3). In age-adjusted analysis PD was associated with a $66 \%$ and $67 \%$ increased risk of 
Table 2. Characteristics of men who had non-fatal (NFMI) and fatal and non-fatal (FNFMI) myocardial infarction $(M I)$

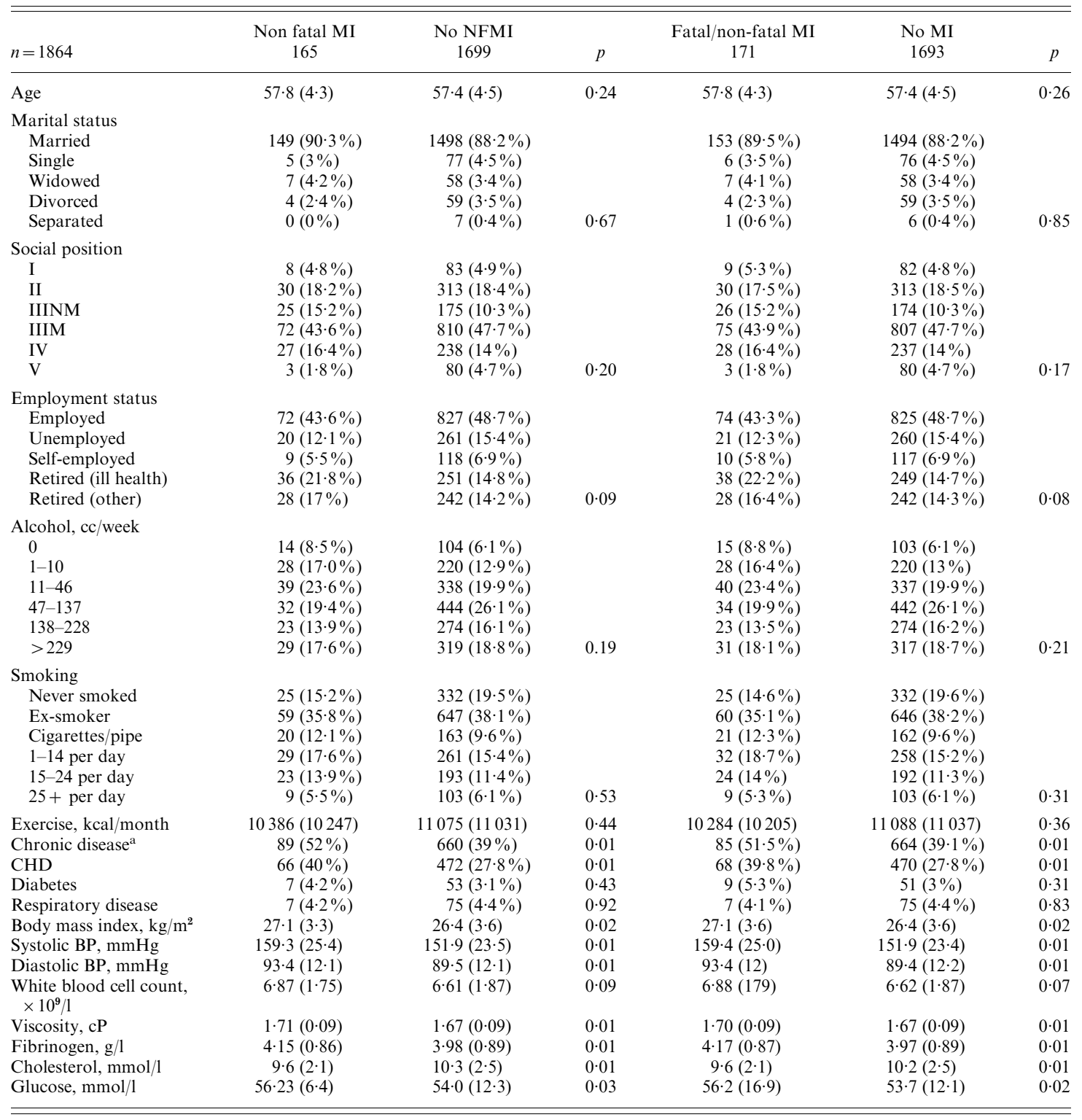

Values are mean (s.D.).

CHD, Coronary heart disease.

a One or more CHD, diabetes, respiratory disease, or retirement due to ill health.

NFMI and FNFMI respectively. Adjustment for smoking attenuated the risk to $63 \%$ for both NFMI and FNFMI. Further adjustment for social position increased the risk of NFMI and FNFMI to $66 \%$ and $67 \%$ respectively. Finally, adjustment for all sociodemographic factors, CHD risk factors and baseline CHD increased the risk slightly of both NFMI and FNFMI to $70 \%$ and $68 \%$ respectively. However, in a fully adjusted analysis excluding participants with 
Table 3. Relative risk (RR) of non-fatal (NFMI) and fatal and non-fatal (FNFMI) myocardial infarction $(M I)$ by psychological distress

\begin{tabular}{|c|c|c|c|c|c|c|c|c|c|}
\hline & CHD events & $\mathrm{RR}^{\mathrm{a}}$ & $95 \% \mathrm{CI}$ & $\mathrm{RR}^{\mathrm{b}}$ & $95 \% \mathrm{CI}$ & $\mathrm{RR}^{\mathrm{c}}$ & $95 \% \mathrm{CI}$ & $\mathrm{RR}^{\mathrm{d}}$ & $95 \% \mathrm{CI}$ \\
\hline NFMI & 165 & $1 \cdot 66$ & $1 \cdot 16-2 \cdot 36$ & $1 \cdot 63$ & $1 \cdot 14-2 \cdot 35$ & $1 \cdot 66$ & $1 \cdot 16-2 \cdot 37$ & $1 \cdot 70$ & $1 \cdot 14-2 \cdot 53$ \\
\hline FNFMI & 171 & $1 \cdot 67$ & $1 \cdot 18-2 \cdot 36$ & 1.63 & $1 \cdot 15-2 \cdot 31$ & $1 \cdot 67$ & $1 \cdot 18-2 \cdot 38$ & $1 \cdot 68$ & $1 \cdot 34-2 \cdot 48$ \\
\hline NFMI (excluding baseline CHD) & 99 & $1 \cdot 59$ & $0 \cdot 99-2 \cdot 55$ & $1 \cdot 56$ & $0 \cdot 97-2 \cdot 51$ & $1 \cdot 56$ & $0 \cdot 97-2 \cdot 51$ & $1 \cdot 67$ & $0 \cdot 96-2 \cdot 91$ \\
\hline FNFMI (excluding baseline CHD) & 103 & 1.59 & $1 \cdot 00-2 \cdot 53$ & $1 \cdot 55$ & $0 \cdot 97-2 \cdot 47$ & $1 \cdot 56$ & $0 \cdot 98-2 \cdot 49$ & $1 \cdot 64$ & $0 \cdot 95-2 \cdot 83$ \\
\hline
\end{tabular}

CHD, Coronary heart disease; $\mathrm{CI}$ : confidence interval.

${ }^{\text {a }}$ Age-adjusted; ${ }^{b}$ age, smoking; ${ }^{\mathrm{c}}$ age, smoking, social class; ${ }^{\mathrm{d}}$ S.D., CHD risk factors and baseline physical illness.

Table 4. Relative risk (RR) of non-fatal (NFMI) and fatal and non-fatal (FNFMI) myocardial infarction $(M I)$ in men by baseline psychological distress and baseline physical illness status

\begin{tabular}{|c|c|c|c|c|c|c|}
\hline & $n$ & $\begin{array}{l}\text { NFMI } \\
\text { FNFMI }\end{array}$ & $\mathrm{RR}^{\mathrm{a}}$ & $95 \% \mathrm{CI}$ & $\mathrm{RR}^{\mathrm{b}}$ & $95 \% \mathrm{CI}$ \\
\hline GHQ negative \& healthy & 926 & $\begin{array}{l}63 \\
64\end{array}$ & $1 \cdot 00$ & $1 \cdot 00$ & $1 \cdot 00$ & $1 \cdot 00$ \\
\hline GHQ positive but healthy & 189 & $\begin{array}{l}17 \\
18\end{array}$ & $\begin{array}{l}1 \cdot 37 \\
1 \cdot 43\end{array}$ & $\begin{array}{l}0 \cdot 78-2 \cdot 41 \\
0 \cdot 83-2 \cdot 48\end{array}$ & $\begin{array}{l}1.63 \\
1.67\end{array}$ & $\begin{array}{l}0 \cdot 90-2 \cdot 95 \\
0 \cdot 93-3 \cdot 00\end{array}$ \\
\hline GHQ negative but ill & 533 & $\begin{array}{l}52 \\
55\end{array}$ & $\begin{array}{l}1.46 \\
1.54\end{array}$ & $\begin{array}{l}1 \cdot 00-2 \cdot 15 \\
1 \cdot 05-2 \cdot 25\end{array}$ & $\begin{array}{l}1 \cdot 36 \\
1 \cdot 40\end{array}$ & $\begin{array}{l}0 \cdot 86-2 \cdot 14 \\
0 \cdot 90-2 \cdot 19\end{array}$ \\
\hline GHQ positive and ill & 216 & $\begin{array}{l}33 \\
34\end{array}$ & $\begin{array}{l}2 \cdot 43 \\
2 \cdot 49\end{array}$ & $\begin{array}{l}1 \cdot 55-3 \cdot 83 \\
1 \cdot 59-3.90\end{array}$ & $\begin{array}{l}2 \cdot 37 \\
2 \cdot 33\end{array}$ & $\begin{array}{l}1 \cdot 33-4 \cdot 20 \\
1 \cdot 32-4 \cdot 12\end{array}$ \\
\hline
\end{tabular}

RR, Relative risk; CI, confidence interval; GHQ, general health questionnaire.

a Age adjusted.

b Baseline s.D., CHD risk factor adjusted.

baseline CHD the association between PD and NFMI and FNFMI was inconclusive. Similarly, the association between PD and NFMI and FNFMI was also inconclusive in an analysis including only those participants with CHD at baseline. Adjusting for baseline CHD alone showed that PD was associated with a $56 \%$ and $58 \%$ increased risk of NFMI and FNFMI respectively.

A test for interaction between PD and physical illness was carried out to understand the interrelationship between physical illness and PD on both NFMI and FNFMI risk. There was very little evidence of an interaction (NFMI, $p=$ $0 \cdot 18$; FNFMI, $p=0 \cdot 18$ ).

Further analysis examined the association between a combination of baseline PD and physical illness status and NFMI and FNFMI (Table 4). In fully adjusted analysis the association between being GHQ-positive but healthy and NFMI and FNFMI was inconclusive, as was the association between being GHQ-negative and physically ill and NFMI and FNFMI. However, being ill and GHQ-positive was associated with greater than twofold increased risk of both NFMI and FNFMI in both age and fully adjusted analyses (Table 4). The magnitude of effects was similar when the more specific baseline CHD was substituted for baseline physical illness.

\section{DISCUSSION}

In this study of a representative sample of middle-aged men PD measured by GHQ caseness was associated with a $70 \%$ and $68 \%$ increased risk of a NFMI and FNFMI respectively. The increased risk changed minimally after adjusting for smoking, social position, and CHD risk factors and prevalent physical illness at baseline. However, PD was not conclusively associated with either NFMI or FNFMI in an analysis excluding men with baseline CHD. Additionally, being physically ill and psychologically distressed was associated with a greater than twofold increased risk of both NFMI and FNFMI.

The prevalence of PD in this cohort was consistent with that found in other community 
populations using the GHQ. Psychological distress was associated with unhealthy behaviours, in particular reduced physical activity. Psychologically distressed men were also more likely to be widowed or divorced, unemployed or retired due to ill health. Distressed men compared with non-distressed men also had higher white blood cell counts, fibrinogen level and greater plasma viscosity. Higher white blood cell counts may be due to chronic physical illness. Indeed the prevalence of chronic illness and the proportion of men who had retired because of ill health was higher in distressed than non-distressed men.

The increased risk of an MI associated with PD in this study is similar to findings reported in two other studies (Barefoot \& Schroll, 1996; Ford et al. 1998). In both of these studies PD was associated with an increased risk of an MI 10 years later.

The average follow-up time for both MI outcomes in this study was 6 years and 4 months. Studies have found an effect of PD on MI at shorter and longer intervals. High hopelessness scores were associated with a greater than twofold increased risk of an MI 6 years later, independently of biological, behavioural, and sociodemographic factors, perceived health status, PD, social support, cancer, history of CVD, and respiratory disease (Everson et al. 1996). In another study (Pratt et al. 1996) respondents with a history of dysphoria were $2 \cdot 1$ times more likely and respondents with MDE 4.5 times more likely to have an MI 13 years later compared with respondents with no history of dysphoria, independently of CHD risk factors, co-morbid psychiatric disorders and psychotropic drug use.

A number of plausible explanations can be suggested to account for the association of PD and increased MI risk. One is that the effect of $\mathrm{PD}$ on MI is mediated through health-related behaviours, especially smoking. However, this is unlikely as a complete explanation as PD has also been found to predict CHD in non-smokers (Anda et al. 1993), and adjustment for smoking in this and other studies (Ford et al. 1998) and other health-related behaviours does not account for the increased risk of MI.

The distress-MI association may also be explained in terms of low socioeconomic position, associated both with PD and MI. It may be that the stresses and strains of low socioeconomic position are associated with PD, which may lead to the development of an MI. If so, then the association between PD and MI should be less evident amongst those in a higher socioeconomic position. However, Ford and colleagues (1998) found an association between PD and MI in American medical students - a group unlikely to be from a low socioeconomic background at the time the sample was selected. Thus, the effect of PD on increased MI risk seen in a sample where increased distress is not associated with low socioeconomic position, and where there is relatively little variation in social position, is unlikely to be due to confounding by socioeconomic position.

Another mechanism may be the association of PD with CHD risk factors. There is some evidence that depressed people have a poorer CHD risk factor profile (Lesperance et al. 1996; Almeida et al. 2006). If CHD risk factors are associated with PD then they might be the link between PD and MI. In this study psychologically distressed men had greater plasma viscosity and fibrinogen level than non-distressed men. Some studies have found that, compared with non-depressed people, depressed people have higher white blood cell count, fibrinogen, factor VIIc and blood platelet activity even in the absence of coronary disease (Kop et al. 2002; Nemeroff \& Musselman, 2000; Shimbo et al. 2002). Thus, one possibility is that the effect of PD on increased MI risk is mediated through haemostatic factors. Nevertheless, adjustment for CHD risk factors did not explain the association of PD and MI in this study.

Another explanation for the association between PD and increased risk of MI is that PD is a consequence of baseline ill-health. In this study there were associations between baseline PD and physical illnesses, especially CHD. Results from some studies have been interpreted as suggesting that the association between PD and CHD is explained by adjustment for ill health (Mendes de Leon \& Krumholz, 1998) whereas other studies still find an increased MI risk associated with $\mathrm{PD}$, even after adjustment for ill health such as cancer, diabetes, stroke, and past CHD (Everson et al. 1996; Ford et al. 1998). However, it is plausible that even after adjustment for ill health, especially using selfreport measures, there remains some residual confounding by physical ill health and this 
may be driving the relationship between PD and increased MI risk. Further, the association of PD and MI may also reflect severity of baseline CHD. Associations between psychosocial factors and disease outcomes have also been explained in terms of negative affectivity - the tendency of participants reporting symptoms of, for example, $\mathrm{CHD}$, also to report more symptoms of PD (Macleod et al. 2002). This may explain why the relationship between PD and MI was inconclusive in an analysis of healthy men, that is, an analysis which excluded men with baseline CHD.

The results of this study suggest that PD is a marker of an underlying chronic physical condition, which increases MI risk. Psychological distress may represent fatigue, malaise or vital exhaustion (Appels, 1997) associated with the pain and discomfort from a chronic physical illness such as CHD. However, the GHQ includes measures of depressive symptoms that are not always present within vital exhaustion (Van Diest \& Appels, 1991), and the 30-item GHQ was derived from the 60-item GHQ precisely in order to avoid contamination by physical illness. Thirdly, the GHQ was designed specifically to screen for psychiatric disorder and its scores correlate with PD and clinical psychiatric disorder. Nonetheless, the GHQ is not a specific measure of depression and may also be detecting generalized anxiety disorder.

There was very little evidence of an interaction between PD and physical illness, although the study had insufficient power to be certain of this. This study did find evidence to suggest that the presence of PD amongst men with a variety of physical illnesses increased the risk of an MI. Though this may be a chance finding resulting from subgroup analyses it nevertheless replicates what we found in earlier analyses in a Scottish cohort study (Rasul et al. 2004). This implies that PD is not merely a confounding factor in the association of PD and MI but has prognostic effects in those who are already physically ill. It has been observed that patients with post-MI depression are more likely to die of cardiac causes than other patients (FrasureSmith, 1991; Parashar et al. 2006). In a study of 222 MI patients, post-MI depression was independently associated with a greater than threefold risk of 6-month mortality, but not with mortality at longer follow-up, independent of severity of disease and cardiac function. This may be because of selective attrition, whereby the more vulnerable depressed patients are dying earlier. However, in another study of patients with significant coronary artery disease, severe and mild depression at the time of coronary angiography was associated with a higher cardiac mortality rate 15 years later (Barefoot et al. 1996). This suggests that depression does not merely lead to early selective mortality but that the effects of post-CHD depression persist for a longer period of time.

A mechanism for the association between PD and MI remains to be identified. Both pathophysiological and social processes may provide the link between PD and MI. Evidence from animal and human studies shows a correlation between increased sympathetic activity and induction of ventricular arrhythmias which can lead to MI (Verrier \& Lown, 1984) and which might be responsible for early events. Psychological distress may cause neuroendocrine disturbances, increased platelet aggregability leading to thrombosis, which may serve to precipitate an MI in people with a chronic disease (Brydon et al. 2006). MIs associated with a depressive state have been attributed to the imbalance between the parasympathetic and sympathetic systems (Appels \& Mulder, 1988). However, in this sample of middle-aged men, influences of PD on slowly developing pathophysiological processes such as atherosclerosis may be the mechanism by which PD exerts its effects over a longer time period. One plausible mechanism is that PD in association with raised hypothalamic-pituitary-adrenal (HPA) drive is influencing endothelial function leading to slowly developing vascular deterioration. This is area that deserves further investigation. Whatever the mechanism, evidence from this and other studies indicates that PD is associated with an increased MI risk in middle-aged men.

\section{ACKNOWLEDGEMENTS}

The work presented in this article was supported by a grant awarded to Professors Stansfeld and Davey Smith from the Special Trustees of the Barts \& The London Hospital Charitable Foundation, which supported a Research Fellowship for Farhat Rasul. 


\section{DECLARATION OF INTEREST}

None.

\section{REFERENCES}

Almeida, O. P., Flicker, L., Hankey, N. P., Vasikaran, S., Van Bockxmeer, F. M. \& Jamrozik, K. (2006). Association of cardiovascular risk factors and disease with depression in later life. American Journal of Geriatric Psychiatry 14, 1-8.

Anda, R., Williamson, D., Jones, D., Macera, C., Eaker, E., Glassman, A. \& Marks, J. (1993). Depressed affect, hopelessness and the risk of ischaemic heart disease in a cohort of U.S. adults. Epidemiology 4, 285-294.

Appels, A. (1997). Exhausted subjects, exhausted systems. Acta Physiologica Scandinavica (Suppl.) 640, 153-154.

Appels, A. \& Mulder, P. (1988). Excess fatigue as a precursor of myocardial infarction. European Heart Journal 9, 758-764.

Barefoot, J. C., Helms, M. J., Mark, D. B. et al. (1996). Depression and long-term mortality risk in patients with coronary artery disease. American Journal of Cardiology 78, 613-617.

Barefoot, J. C. \& Schroll, M. (1996). Symptoms of depression, acute myocardial infarction and total mortality in a community sample. Circulation 93, 1976-1980.

Brydon, L., Magid, K. \& Steptoe, A. (2006). Platelets, coronary heart disease and stress. Brain, Behaviour and Immunity 20, 113-119.

Caerphilly and Speedwell Collaborative Group (1984). Caerphilly and Speedwell collaborative heart disease studies. Journal of Epidemiology and Community Health 38, 259-262.

Carney, R. M., Freedland, K. E., Rich, M. W. \& Jaffe, A. S. (1995). Depression as a risk factor for cardiac events in established coronary heart disease; a review of possible mechanisms. Annals of Behavioural Medicine 17, 142-149.

Everson, S. A., Goldberg, D. E. \& Kaplan, G. A. (1996). Hopelessness and risk of mortality and incidence of myocardial infarction and cancer. Psychosomatic Medicine 58, 113-121.

Ford, D. E., Mead, L. A., Chang, P. P., Cooper-Patrick, L., Wang, N. \& Klag, M. J. (1998). Depression is a risk factor for coronary artery disease in men. The Precursors Study. Archives of Internal Medicine 158, 1422-1426.

Frasure-Smith, N. (1991). In-hospital symptoms of psychological stress as predictors of long-term outcome after acute myocardial infarction in men. American Journal of Cardiology 67, 121-127.

Glassman, A. H. \& Shapiro, P. A. (1998). Depression and the course of coronary artery disease. American Journal of Psychiatry 155, 4-11.

Goldberg, D. (1972). The Detection of Psychiatric Illness by Questionnaire. Maudsley Monograph No. 21. Oxford University Press: Oxford.

Hemingway, H. \& Marmot, M. (1999). Psychosocial factors in the aetiology and prognosis of coronary heart disease: systematic review of prospective cohort studies. British Medical Journal $\mathbf{3 1 8}$ $1460-1467$.

Hippisley-Cox, J., Fielding, K. \& Pringle, M. (1998). Depression is a risk factor for ischaemic heart disease in men: population based case-control study. British Medical Journal 316, 1714-1719.

Kop, W. J., Gottdiener, J. S. \& Tangen, C. M. (2002). Inflammation and coagulation factors in persons $>65$ years of age with symptoms of depression but without evidence of myocardial ischemia. American Journal of Cardiology 89, 419-424.

Lesperance, F., Frasure-Smith, N. \& Talajic, M. (1996). Major depression before and after myocardial infarction: its nature and consequences. Psychosomatic Medicine 58, 99-110.
Macleod, J., Davey Smith, G., Heslop, P., Metcalfe, C., Carroll, D. Hart, C. \& Lynch, J. (2002). Psychological stress and cardiovascular disease: empirical demonstration of bias in a prospective observational study of Scottish men. British Medical Journal 324, 1247-1251.

Mendes-de-Leon, C. F. \& Krumholz, H. M. (1998). Depression and risk of coronary heart disease in elderly men and women: New Haven EPESE, 1982-1991. Established Populations for the Epidemiologic Studies of the Elderly. Archives of Internal Medicine 158, 2341-2348.

Nemeroff, C. B. \& Musselman, D. L. (2000). Are platelets the link between depression and ischemic heart disease? American Heart Journal 140, 57-62.

Nicholson, A., Kuper, H. \& Hemingway, H. (2006). Depression as an aetiologic and prognostic factor in coronary heart disease: a meta-analysis of 6362 events among 146538 participants in 54 observational studies. European Heart Journal 27, 2663-2774.

Parashar, S., Rumsfeld, J.S., Spertus, J. A., Reid, K. J., Wenger, N. K., Krumholz, H. K., Amin, A., Weintraub, W. S., Lichtman, J., Dawood, N. \& Vaccarino, V. (2006). Time course of depression and outcome of MI. Archives of Internal Medicine 166, 2036-2043.

Pratt, L., Ford, D., Crum, R., Armenian, H., Gallo, J. \& Eaton, W. (1996). Coronary heart disease/myocardial infarction: depression, psychotropic medication, and risk of myocardial infarction: prospective data from the Baltimore ECA follow-up. Circulation 94, 3123-3129.

Rasul, F., Stansfeld, S. A., Hart, C. \& Davey Smith, G. (2004) Psychological distress, physical illness and coronary heart disease. Journal of Epidemiology and Community Health 59, 140-145.

Rose, G. A. (1962). The diagnosis of ischaemic heart disease and intermittent claudication in field surveys. Bulletin WHO 27, 645-658.

Shimbo, D., Child, J. \& Davidson, K. (2002). Exaggerated serotoninmediated platelet reactivity as a possible link in depression and acute coronary syndromes. American Journal of Cardiology $\mathbf{8 9}$, 331-333.

Stansfeld, S. A., Fuhrer, R., Shipley, M. J. \& Marmot, M. G. (2002). Psychological distress as a risk factor for coronary heart disease in the Whitehall II study. International Journal of Epidemiology 31, 248-255.

Stansfeld, S. A., Sharp, D. S., Gallacher, J. E. J. \& Yarnell, J. W. G. (1992). A population survey of ischaemic heart disease and minor psychiatric disorder in men. Psychological Medicine 22 , 939-949.

Van Diest, M. J. \& Appels, A. (1991). Vital exhaustion and depression: a conceptual study. Journal of Psychosomatic Research 35, 535-544.

Verrier, R. L. \& Lown, B. (1984). Behavioural stress and cardiac arrythmias. Annual Review of Physiology 46, 155-176.

Wassertheil-Smoller, S., Applegate, M. D., Berge, K., Chang, C. J. Davis, B. R., Grimm, R., Kostis, J., Pressel, S. \& Schron, E. (1996). Change in depression as a precursor of cardiovascular events. Archives of Internal Medicine 156, 553-561.

WHO Regional Office for Europe (1976). Myocardial infarction community registers. Results of WHO international collaborative study. WHO Regional Office for Europe: Copenhagen, Denmark

Wulsin, L. R. \& Singal, B. (2003). Do depressive symptoms increase the risk for the onset of coronary disease? A systematic quantitative review. Psychosomatic Medicine 65, 201-210.

Wulsin, L. R., Evans, J. C., Ramachandaran, V. S., Murabito, J. M., Kelley-Hayes, M. \& Benjamin, E. J. (2005). Depressive symptoms, coronary heart disease, and overall mortality in the Framingham Heart Study. Psychosomatic Medicine 67, 697-702. 